\title{
Analysis and Investigation of Ms Weldment Using Unbaked E7018 Electrode
}

\author{
Dr. B. Vijaya kumar ${ }^{1}$, N. Yashwanth ${ }^{2}$, P. Madhav², P. Srinath ${ }^{2}$, N. Pradeep ${ }^{2}$ \\ ${ }^{1}$ Professor, HOD, 2 UG Scholar \\ 1,2Department Mechanical Engineering, GNIT, Rangareddy, Telangana, India
}

\begin{abstract}
How to cite this paper: Dr. B. Vijaya kumar | N. Yashwanth | P. Madhav | P. Srinath | N. Pradeep "Analysis and Investigation of Ms Weldment Using Unbaked E7018 Electrode " Published in International Journal of Trend in Scientific Research and Development (ijtsrd), ISSN: 24566470, Volume-3 | Issue-3, April 2019, pp.1168-1172, URL: https://www.ijtsrd.c om/papers/ijtsrd23 307.pdf

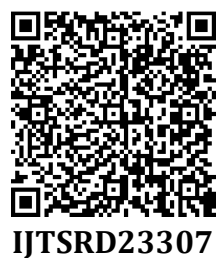

Copyright (C) 2019 by author(s) and International Journal of Trend in Scientific Research and Development Journal. This is an Open Access article distributed under the terms of the Creative Commons

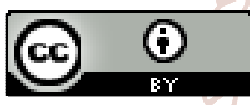
Attribution License (CC BY 4.0) (http://creativecommons.org/licenses/ by/4.0)
\end{abstract}

\section{INTRODUCTION}

Shielded metal arc welding (SMAW), also known as manual metal arc welding. It is least expensive, and most widely used arc welding process. This process produces coalescence of metals by heating them with an arc between a covered metal electrode and the base metal work piece. The temperature of about $4000^{\circ} \mathrm{c}$ is produced to melt the electrode. Shielding is provided by decomposition of the electrode covering. The main function of the shielding is to protect the arc and the hot metal from chemical reaction with constituents of the atmosphere. In this both AC and DC power supply can be used. The arc is produced at high current $80 \mathrm{amps}$ to $300 \mathrm{amps}$ and voltage upto $20 \mathrm{~V}$ to $70 \mathrm{~V}$. The electrode covering contains fluxing agents, scavengers. Pressure is not used in the process, and the filler metal is obtained from the electrode. All ferrous metals can be welded in all positions using SMAW. In this method, the porosity is often not visible without the use of advanced nondestructive testing methods, and this defect usually strongly affects the strength and the quality of the weld. This welding process is used for carbon steel, low alloy steel, high alloy steel, stainless steel, cast iron, and ductile iron.

\section{EXPERIMENTAL WORK}

The specimen of material IS 2062 Grade B mild steel of dimensions length $150 \mathrm{~mm}$, width $150 \mathrm{~mm}$ and thickness $8 \mathrm{~mm}$ is taken.

\subsection{GROOVE PREPARATION}

The test specimen before welding, edge preparation and groove preparation must be done. The groove angle of $30 \mathrm{deg}$ for two specimens is prepared with the help of grinding. Then we get a shape of ' $V$ ' when two specimens are joined together.

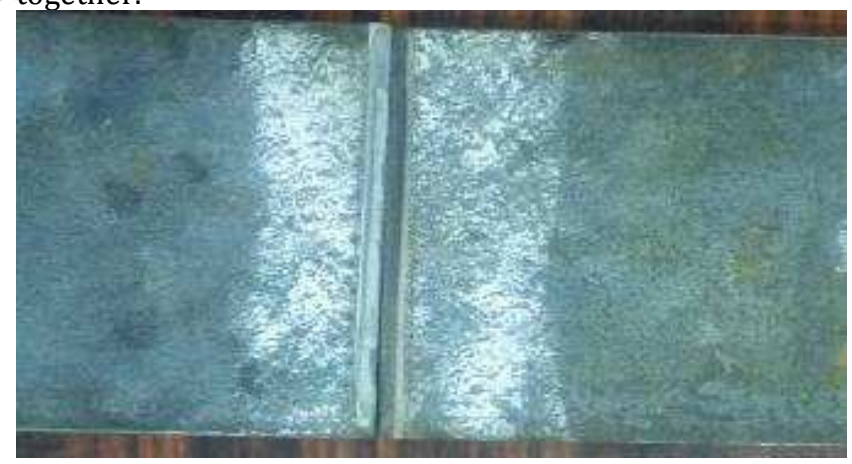

Fig 1: V groove preparation

\subsection{WELDING WITH E7018 ELECTRODE}

The weld specimens after $\mathrm{V}$ groove preparation welding process will be done on both face and root layer. For welding the specimens we use two electrodes of different diameter $2.5 \mathrm{~mm}$ and $3.15 \mathrm{~mm}$ with different voltage and current. The gap between the two specimen is upto $2 \mathrm{~mm}$. For face layer welding firstly we use $2.5 \mathrm{~mm}$ diameter of electrode with voltage $20 \mathrm{~V}$ and current $100 \mathrm{amps}$ is used after that for 
second layer we use $3.15 \mathrm{~mm}$ diameter of electrode with voltage $25 \mathrm{~V}$ and current $120 \mathrm{amps}$ is used. Next the root layer is welded with $2.5 \mathrm{~mm}$ diameter of electrode with voltage $20 \mathrm{~V}$ and current $100 \mathrm{amps}$ is used. After welding with help of spatter slag should be removed and with the wire brush the weld joint is cleaned.

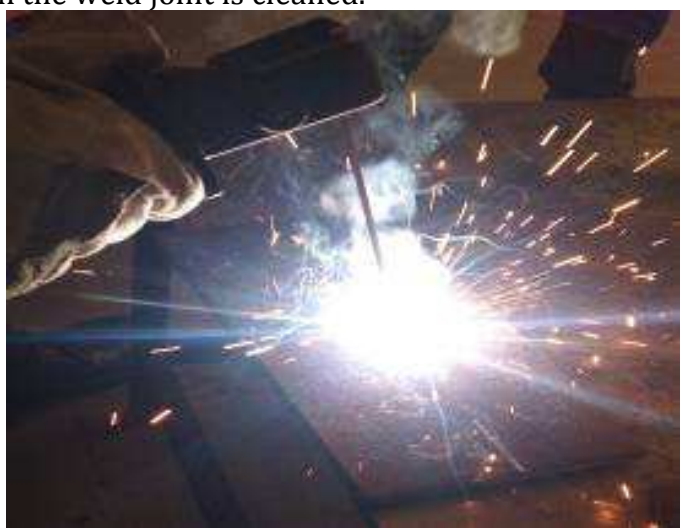

Fig 2: Welding the specimen with E7018

\subsection{LEEB HARDNESS TEST}

Hardness testers using Leeb's method operate in a slightly different manner as compared to standard testing methods like Vickers, Rockwell or Brinell. The hardness is indirectly measured via the loss of energy of a so-called impact body. A mass is accelerated to the surface of the test object and impinges on it at a defined speed, i.e. kinetic energy. The impact creates a plastic deformation of the surface, i.e. an indentation, due to which the impact body loses part of its original speed - or energy. It will lose more speed by creating a bigger indentation and, thus, at softer material.

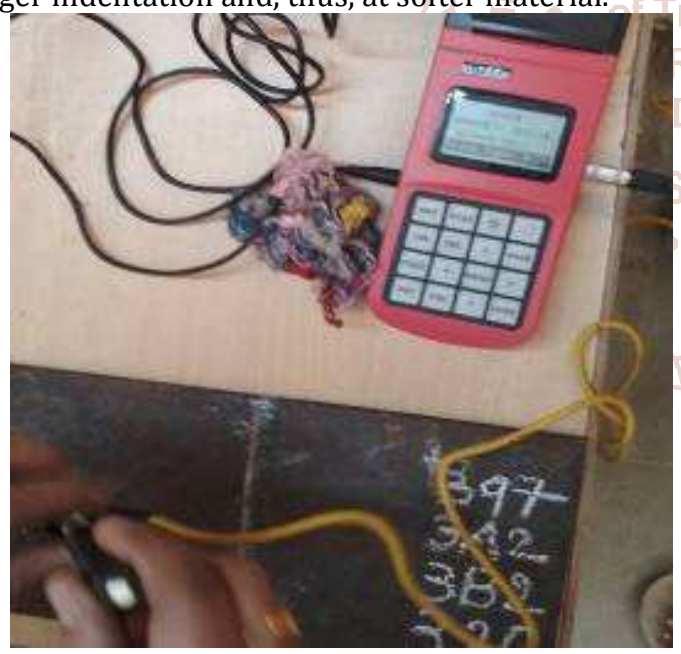

Fig 3: Leeb harness tester

\subsection{DYE PENETRATE TEST}

Dye penetration test is also called as liquid penetrant testing. It is one of the earliest methods used for non-destructive inspection and has been a mainstay of practical ndt for many years. it is the most common ndt method (apart from visual inspection) used for the detection of surface breaking cracks in metal components. It is used on both face and root layer.

The steps are:

1. Pre-cleaning

2. Application of penetrate

3. Dwell time

4. Excess removal of penetrate

5. Application of developer

6. Inspection

7. Post cleaning

\section{A. Pre-cleaning}

In this step the weldbead is cleaned to remove all traces of foreign material, grease, dirt etc. To get better results in inspection.

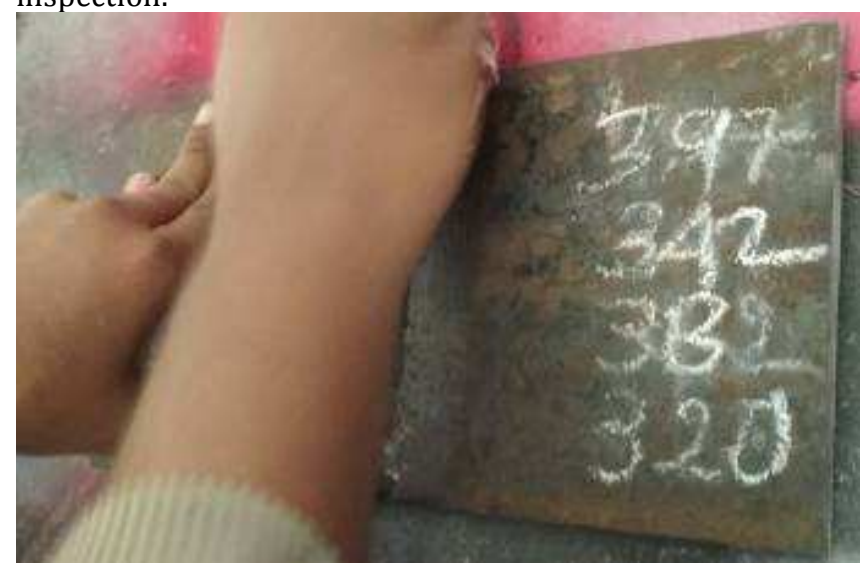

Fig 4: Pre-cleaning the weld specimen

\section{B. Application of penetrate}

After pre-cleaning the weldbead, we apply penetrate on the surface of the weldbead. This penetrate is red in colour so it is helps us to detect defects easily.

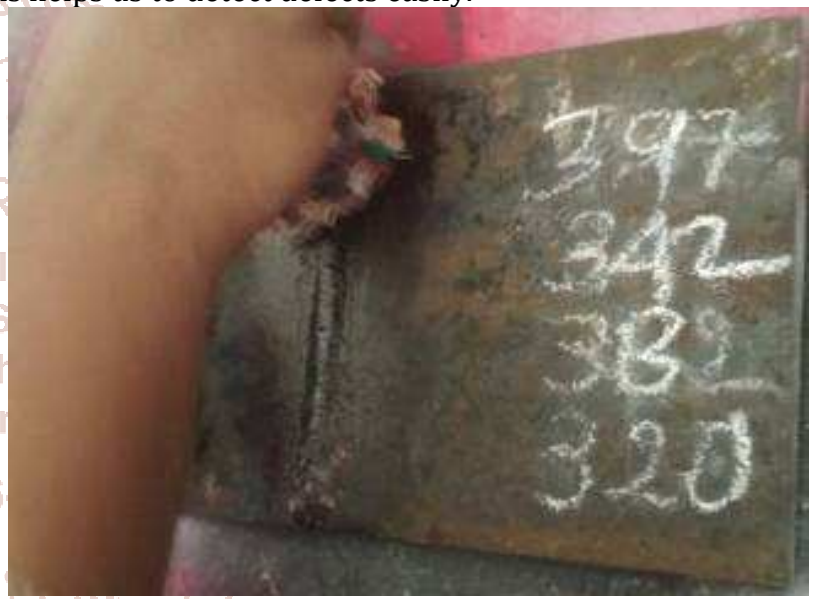

Fig 5: Application of penetrate

\section{Dwell time}

The penetrate which we apply on weldbead to detect defects requires time to settle because of capillary action it may take 10 to 60 minutes to settle. So that we can get exact defects.

\section{Excess removal of penetrate}

After applying the penetrate on the weld surface the excess penetrate is removed so that we can get exact defects or else the penetrate applied on the weld surface will make the defects covered so that we can't see defects.

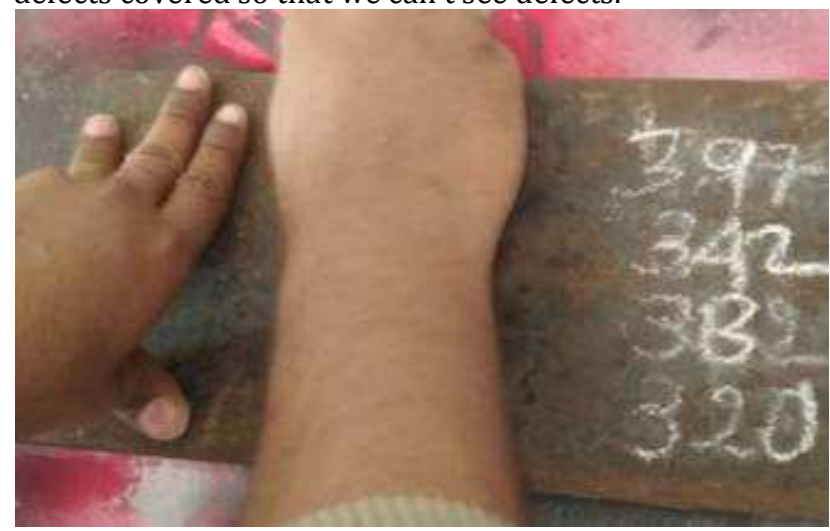

Fig 6: Excess removal of penetrate 


\section{E. Application of developer}

A thin layer of developer is then applied to the sample to draw penetrate trapped in flaws back to the surface where it is visible. Developers come in variety of forms that may be applied by dusting, dipping and spraying.

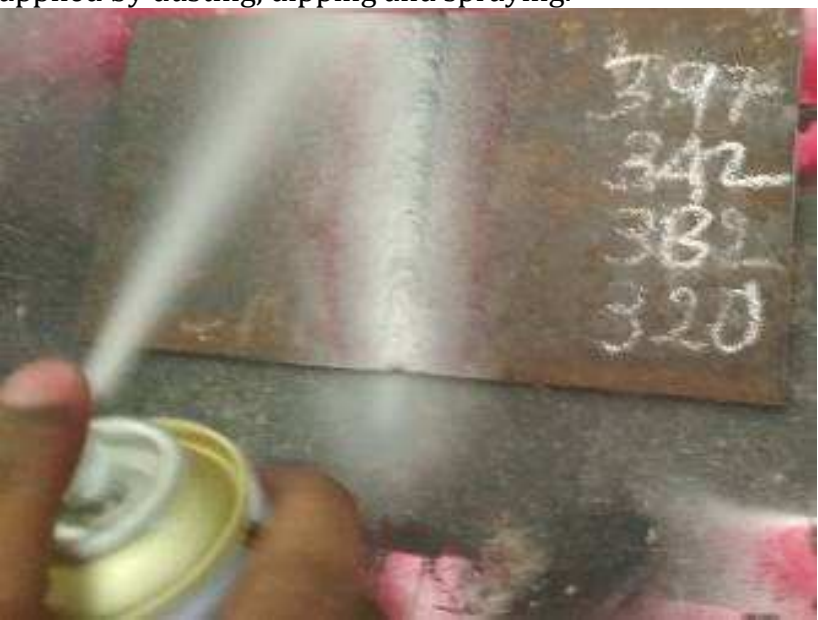

Fig 7: Applying developer

\section{F. Inspection}

In this step we clearly see the defects which occur on weld bead after application of developer.

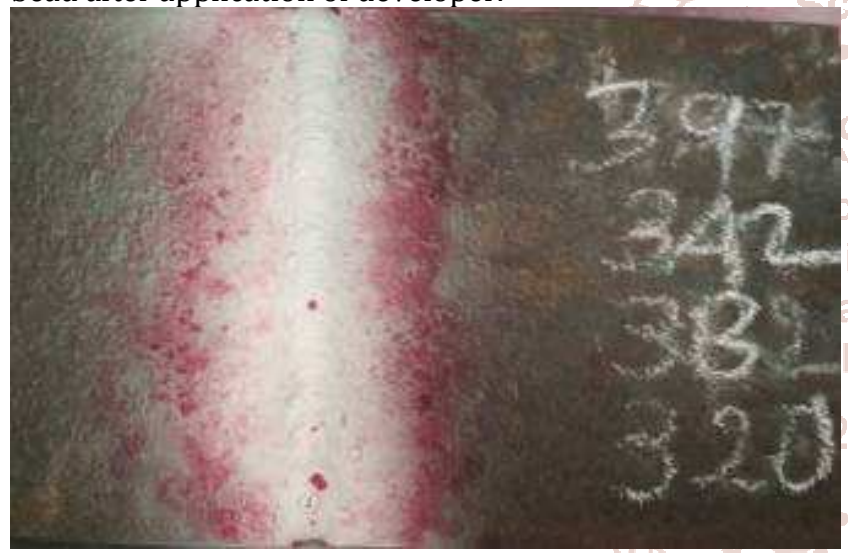

Fig 8: Defects on face layer

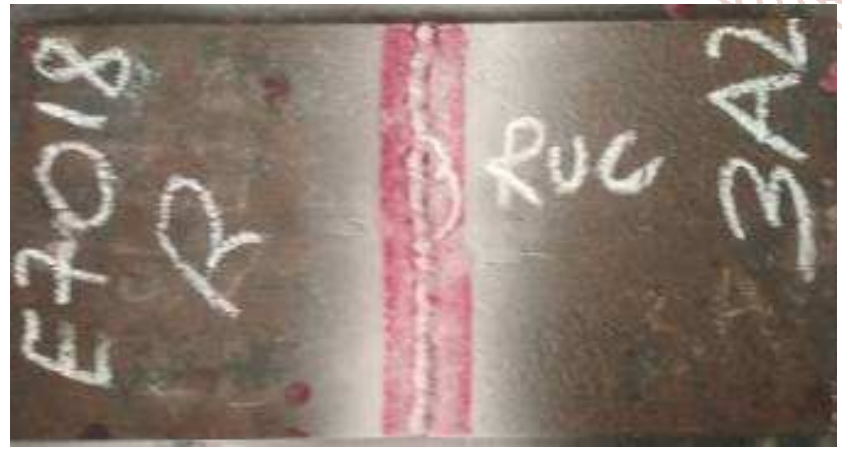

Fig 9: Defects on root layer

\subsection{MAGNETIC PARTICLE TEST}

Magnetic particle testing (MPT) is one of the most widely used non-destructive testing. This method uses magnetic fields and small magnetic particles to detect flaws in specimen to be tested. The only requirement is that the component being inspected must be made of a ferromagnetic material.

The magnetic penetration test can be done in following sequential manner
1. Pre-cleaning

2. Magnetization in longitudinal direction

3. Inspection

4. Demagnetization

\section{A. Pre-cleaning}

In this step the weldbead is cleaned to remove all traces of foreign material, grease, dirt etc. To get better results in inspection.

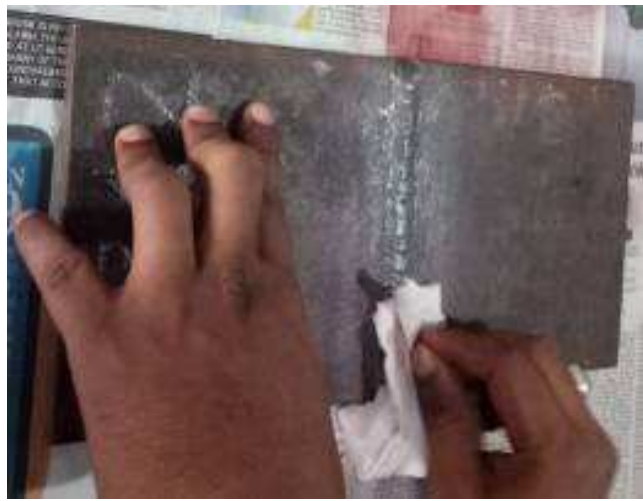

Fig 10: Pre-cleaning

\section{B. Magnetization in longitudinal direction}

In this step first we need to spray contrast spray on the weld joint then the weld joint is placed in between the legs of magnetic yoke which has two legs with spacing of 8 inch and width minimum 3 inch. After the yoke switched on the magnetic lines travelles perpendicular to direction of current. Then the magnetic powder is sprinked on the weld joint in between yoke legs. So that we can see the defect of surface or sub surface. This process is done upto the weld joint length

Voltage: $220 \mathrm{~V}$

Current: 2.2Amps

$>$ Frequency: $50 \mathrm{~Hz}$

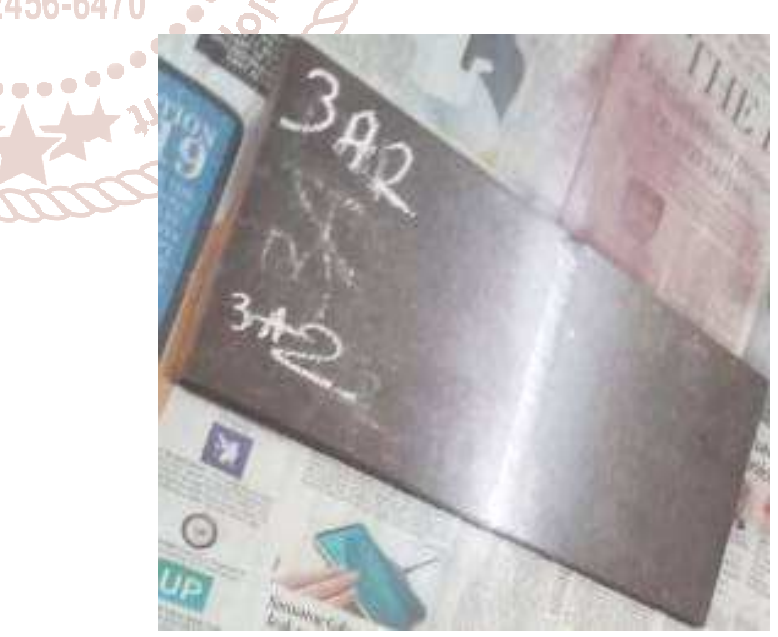

Fig 11: Applied contrast paint

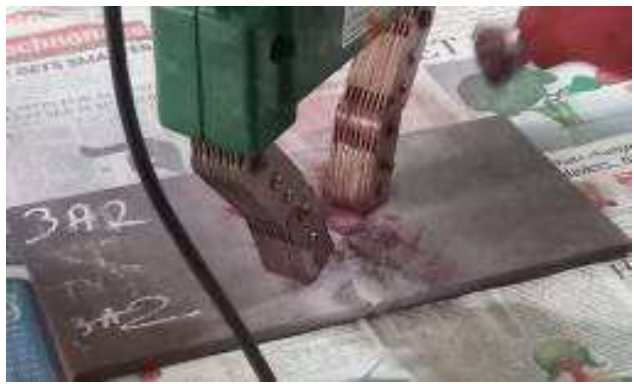

Fig 11: Spraying magnetic powder 


\section{Inspection}

After spraying the magnetic particles due to magnetic yoke the magnetic lines which pass between two legs of yoke. If the defect is present the lines break and we can see the particles gather at that point.

\section{Demagnetization}

After identified the defects, we must demagnetize the metal. The demagnetization can be done with changing the direction of magnetic yoke. If any magnetization is present on the weld metal, further operations the efficiency may be reduced. The magnetization up to $+3 \mathrm{~mm}$ to $-3 \mathrm{~mm}$ is negligible.

\subsection{RADIOGRAPHY TEST}

NDT techniques have been employed to test a material for surface or internal flaws without interfering in any way with its suitability for service. Radiography (X-rays or sometimes gamma rays) seems to be the most effective method and the experts are able to identify most types of defects in the images produced by this method. The method is based on the fact that the defective areas absorb more energy and thus the defects appear darker in the image. A detector is lined up with the beam on the other side of the item. The detector records $\mathrm{x}$-rays or gamma rays that pass through the material. The thicker the material, the fewer $x$-rays or gamma rays can pass through. Because the material is thinner where there is a crack or flaw, more rays pass through that area. The detector captures the rays that pass through, which form a picture of the crack or flaw ${ }^{[5]}$.

\subsection{BENDING TEST}

Bend test is one of the most important and commonly used destructive tests to determine the ductility and soundness (for the presence porosity, inclusion, penetration and other internal weld discontinuities) of the weld joint produced using under one set of welding conditions. The test is conducted on both face and root layer.

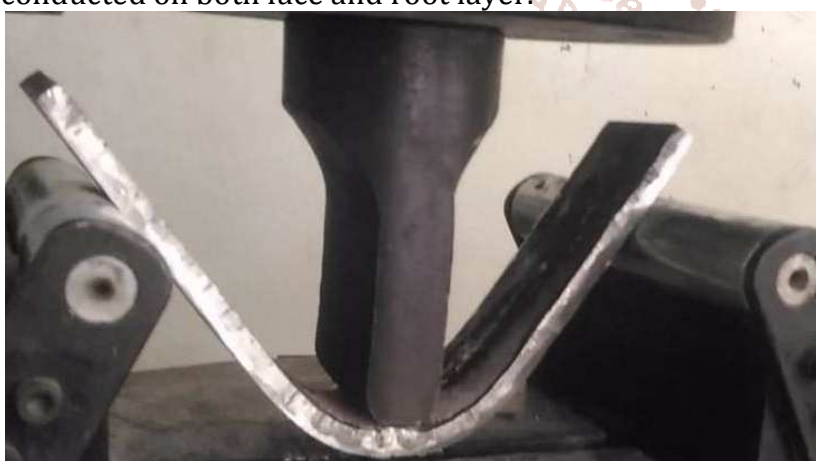

Fig 12: Bending test

\subsection{TENSILE TEST}

Tensile strength is the maximum stress that a material can sustain in tension. In other words we can say the amount of applied load per cross sectional area that a material can withstand before failure. Mathematically it is calculated as the ratio of maximum tensile load to the original cross section area. ${ }^{[4]}$ Tensile properties of the weld joints can be obtained either in ambient condition or in special environment (low temperature, high temperature, corrosion etc.) depending upon the requirement of the application using tensile test which is usually conducted at constant strain rate.

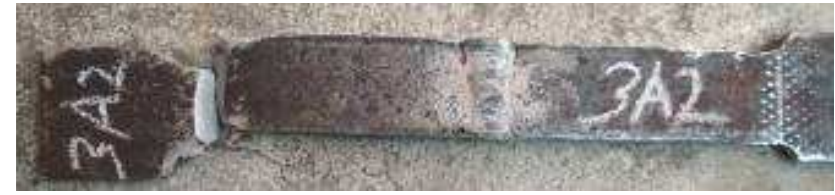

Fig 13: Tensile test

\section{RESULTS AND DISCUSSIONS}

3.1 HARDNESS TEST RESULTS ON E7018 WELD METAL

We get the following hardness values, while measuring the E7018 weld plate

Table 1: Leeb Hardness Test values on E7018 weld metal

\begin{tabular}{|c|c|c|c|c|c|c|}
\hline $\begin{array}{c}\text { Positi } \\
\text { on }\end{array}$ & $\begin{array}{c}\text { Bas } \\
\text { met } \\
\text { al } \\
\text { (B1) }\end{array}$ & $\begin{array}{c}\text { HA } \\
\text { Z } \\
\text { (H1 }\end{array}$ & $\begin{array}{c}\text { Positi } \\
\text { on }\end{array}$ & $\begin{array}{c}\text { Weld } \\
\text { ed } \\
\text { area } \\
\text { (W1) }\end{array}$ & $\begin{array}{c}\text { HA } \\
\text { Z } \\
\text { (H2 }\end{array}$ & $\begin{array}{c}\text { Bas } \\
\text { e } \\
\text { met } \\
\text { al } \\
\text { (B2) }\end{array}$ \\
\hline Top & 437 & 369 & Top & 352 & 346 & 344 \\
\hline Middle & 387 & 350 & Middle & 371 & 408 & 360 \\
\hline $\begin{array}{c}\text { Botto } \\
\text { m }\end{array}$ & 340 & 348 & $\begin{array}{c}\text { Botto } \\
\text { m }\end{array}$ & 454 & 334 & 365 \\
\hline
\end{tabular}

\section{RESULTS OF DYE PENETRATION TEST (DPT)}

On E7018 weld metal we observe following defects on face layer we observe pin holes (PH), on root layer we observe root under cut (RUC).

\section{RESULTS OF MAGNETIC PARICLE TEST(MPI)}

MPI test is used to determine the surface and sub-surface defects on weldment. We conducted the MPI test on weldment welded by unbaked E7018 electrode we got two defects one is blow hole(BH) and the other is under cut (UC)

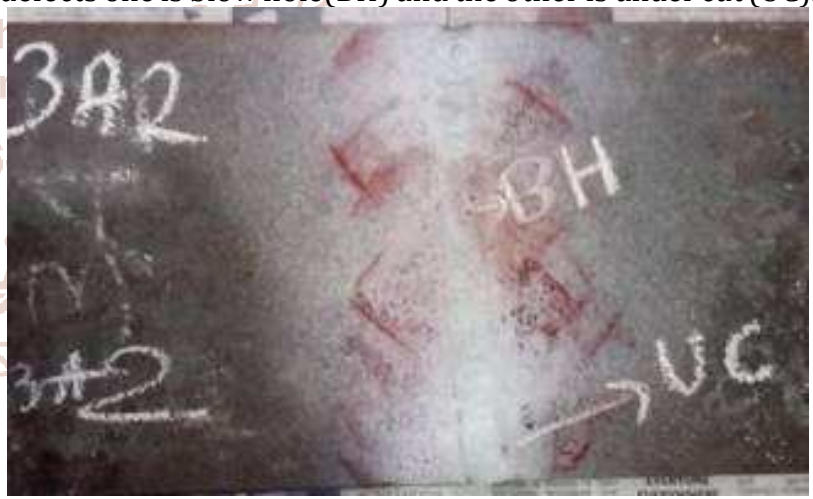

Fig 14: MPI test defects on weldment

\section{RESULTS OF RADIOGRAPHY TEST}

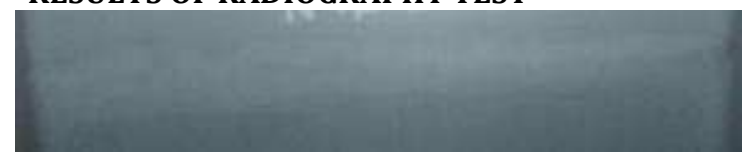

Fig 15: Radiography test

4. RESULTS OF TENSILE TEST

Tensile strength results on E7018 weld metal

\begin{tabular}{|c|c|}
\hline Load (KN) & Deflection (mm) \\
\hline 127 & 30 \\
\hline
\end{tabular}

\section{RESULTS OF BENDING TEST}

Bending test results for E7018 weld metal \begin{tabular}{l|l|l|}
\hline Position & Load (KN) & Deflection ( $\mathrm{mm}$ ) \\
\hline
\end{tabular}

\begin{tabular}{|c|c|c|}
\hline Face & 150 & 90 \\
\hline Root & 55 & 85 \\
\hline
\end{tabular}




\section{CONCLUSION}

$>$ Recently developed low hydrogen basic coated electrodes deposit weld metal having improved toughness properties and low level hydrogen. These electrodes almost eliminate risk of cold cracking.

$>$ Hydrogen control assumes criticality as the hardenability increases.

$>$ Hydrogen is an elusive element affecting cold cracking susceptibility in ferritic welds.

$>$ To have longer shelf life and cut down cost of welding, fabricators prefer vacuum packed basic coated low hydrogen electrodes.[3]

$>$ When low hydrogen (E7018) electrode is used, the weld is smooth as compared to the other electrode with less slag[1].

\section{REFERENCES}

[1] Impermeable Low Hydrogen Covered Electrodes: Weld Metal, Slag, and Fumes Evaluation Cláudio TuraniVaz, Alexandre QueirozBracarense, IvanilzaFelizardo, Ezequiel CairesPereira Pessoa in Material science and Technology (volume 1) September 2012.

[2] Improvement of impact toughness of AWS E7018 weld metal by adding TiO2 nanoparticles to the electrode coating in M. P. Dhanukanano technology and advanced materials July 2008.

[3] Md. Anis Raza, Sudhir Kumar Kashyap, Rakesh The effect of welding on mechanical and microstructural properties of material 2016.

[4] Christopher T. Mgonja F. Ansari, in Service Life Estimation and Extension of Civil EngineeringStructures, 2017. 